Send your letters to the editor, British Dental Journal, 64 Wimpole Street, London W1G 8YS E-mail bdj@bda.org

Priority will be given to letters less than 500 words long. Authors must sign the letter, which may be edited for reasons of space

\section{Uncertainty and delay}

Sir, please find below a copy of the email that I sent to the CDO on 13 July 2005. To date I have received neither a reply or even an acknowledgement. I hope that publication in a prestigious journal like yours will bring to light the acute mental distress that I and many others in India were made to suffer.

Letter to the CDO, DOH dated 13 July 2005 Sir, I am a 42-year-old dentist and have been a private GDP since January 1987. This means that it is more than 20 years since I read textbooks in any intensive way for a prolonged period of time. When I learnt in December 2004 that the IQE 'A' exam was being held in India for the first time, I was still hesitant about appearing for it because of the high cost of the exam as well as doubts about my chances of success. I made the final decision to appear for the IQE with not a little trepidation. The one factor which swung the decision was the prospect of Clinical Attachment positions that were to be offered to successful candidates of IQE 'A' who sat the exam in India. I was confident that if I cleared the exam, I would be offered the support of the Clinical Attachment Scheme while I appeared for Parts 'B' and ' $C$ ' of the IQE. As soon as I found out about my successful result, you cannot imagine the euphoria that I experienced. I was certain that the most difficult first step towards my joining the NHS was taken. I little expected the agonies of uncertainty and delay that most of us Indian candidates are now being subjected to. I have already asked for a postponement of my IQE ' $\mathrm{B}$ ' date once in June, and I will most probably have to do so again as I have to give a reply to the GDC exam council by 19 July regarding acceptance or postponement of my Sept 20 IQE 'B' exam seat offer by GDC. We were led to believe that the Department of Health would pay for the Part 'B' exam once we joined the Clinical Attachment scheme, but now that there is a fog of uncertainty over the whole scheme, I dare not accept the IQE 'B' exam offer as I have no assurance from you that I will be placed in the scheme before 20
Sep 2005. I, like many other candidates from India, am not in a position to appear for the IQE 'B' and 'C' without the support of the Clinical Attachment Scheme. I would appreciate it if you or somebody else in a responsible position would explain the exact status of the scheme and the reasons for this unconscionable delay which is causing me and many others quite a lot of mental distress.

\section{S. Raghavan}

By email

Chief Dental Officer Professor Raman Bedi responds: The Department did not guarantee at the time IQE Part A was held in India that all candidates would be offered places on the clinical attachment scheme. We have since offered dentists who took IQE Part A reimbursement of their Part B fees, whether or not they have been placed in the clinical attachment scheme. The provision of IQE Part A in India, the further support for Indian candidates and the additional sittings of IQE in the UK have significantly widened access to NHS dentistry for Indian dentists. doi: 10.1038/sj.bdj.4812853

\section{Double standard?}

Sir, I would like to expand on the points made by your correspondent $\mathrm{P}$. Tweddell (BDJ 2005; 199: 128). I absolutely agree that as health care professionals we have an obligation to treat all individuals and we are expected to have proper infection control systems in place in order to minimise the risks that arise. Statistics suggest that the risk of infection of health care workers is very low but of course it can never be zero, any more than the risk is zero in the wider world. If you choose a career tending the sick there will always be the possibility that it may do you harm, but that is a risk which must be accepted. That is why I am vehemently opposed to the other aspect of the situation, which is the policy towards infected health care workers. This has gone a stage further in now requiring new graduates to demonstrate that they are 'clean' before they are allowed on to the register. This is a policy which sends two negative messages. Firstly, if our infection control procedures are satisfactory, it ought not to be an issue, and

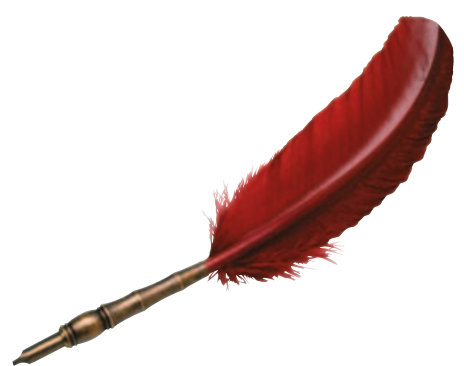

GDC policy must be seen as questioning that fact. Secondly and perhaps more importantly is the human rights issue. While patient safety is clearly important, I cannot accept that the public has any more fundamental right to safety than health care workers. I believe that GDC policy constitutes a double standard and I am disappointed that our regulatory body is not more robust in espousing this position.

P. Maund

Ferring

doi: $10.1038 /$ sj.bdj.4812854

\section{Harsh advice?}

Sir, the sentiments expressed by $\mathrm{P}$. Tweddell (BDJ 2005; 199: 128) are worthy of further comment. The Centers for Disease Control, Atlanta, USA stated in December 2003:

'The Hepatitis C virus appears not to be transmitted efficiently through occupational exposure to blood.'

'No studies of transmission from HCVinfected dental care personnel to patients have been reported, and the risk for such transmission appears limited.'

The Centers noted that transmission from HCV-infected surgeons during invasive procedures was on average $0.17 \%$. Given these findings, the GDC's advice that HVC-infected dentists should cease practising appears to be harsh and not supported by the current evidence.

J. Hardie

Lisburn

The Chief Executive and Registrar of the General Dental Council, Antony Townsend responds: Thank you for the opportunity to reply to the recent letters to the $\mathrm{BDJ}$ on the subject of blood borne viruses.

The GDC's purpose is to protect patients. To do this we must make a number of checks on each applicant's suitability for registration. We ask all applicant dentists to submit a health certificate as evidence of their good health. This is not new, but last year we made the check more robust by stipulating the sorts of health issues we would expect to be told about. Currently, we require evidence of $T B$ and hepatitis B immunity. This is 


\section{LETTERS}

consistent with the practice of NHS employers and dental schools. While its principal purpose is to protect patients, establishing immunity is also in the clinician's interests.

Mr Tweddell is not right to say that a dentist infected with a blood borne virus 'would be legally obliged to inform the GDC, who would subsequently advise the dentist to cease practice. The GDC's guidance is that a dentist who knows they are, or thinks they may be, infected with a blood borne virus or any other transmissible disease or infection, has a duty to seek and follow medical advice. The medical adviser will be obliged to follow the procedures clearly outlined by the Department of Health. These procedures are under continual review by a range of expert groups including the Expert Advisory Group on AIDS (EAGA), the Advisory Group on Hepatitis (AGH) and the UK Advisory Panel for Health Care Workers Infected with Blood-borne Viruses (UKAP). The GDC expects each registrant to ensure that the national guidelines on infected health care workers are followed for the protection of patients. Since the majority of procedures carried out by dental surgeons are exposure-prone as defined by the Department of Health, it is inevitable that on some occasions the individual will have to cease the clinical practice of dentistry either temporarily or permanently. doi: 10.1038/sj.bdj.4812855

\section{Must-have kit}

Sir, in the current climate of worry over cross infection, manpower, funding, and registration, how refreshing it was to be updated on the latest must-have maxillofacial kit.(BDJ 2005; 199: 129).

I too have my own dental kit receptacle which I also believe to have not been previously described in the literature.

In design it has all the necessary features. It is compact, light-weight, multi-purpose, and weather-proof. It also has the advantage of being disposable, and it claims to be degradable.

It measures $300 \mathrm{~mm} \times 300 \mathrm{~mm}$ and has a single opening with two handles cleverly located at its top for the purposes of carrying. Please see photograph.

It has a large capacity for holding a multitude of instruments and materials, and a many other things besides. It comes in a variety of colours, with or without logos, and is available from most stores throughout the UK. And for those of us working under the constraints of the General Dental Services, here's the best bit: it comes free of charge!

P. Ireland

By email

doi: 10.1038/sj.bdj.4812856

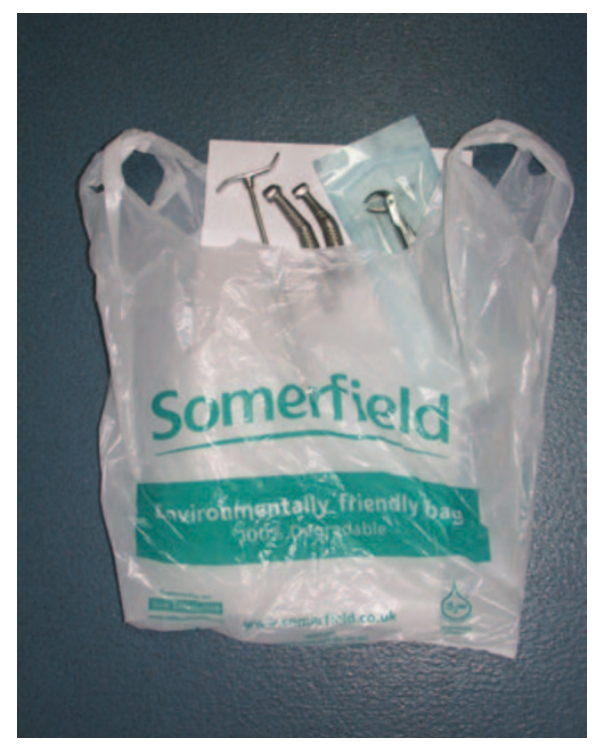

according to Whitley terms based on the provisions of department of health circular PM 81 (30).

My case has still not been resolved by the health authority and has now been referred to the Department of Health.

I'm sure there are many out there who find themselves in similar positions. The problem is that health authorities have no clear guidelines to work from and the pay scales between community and hospital are different. This unfortunately creates problems when you interchange jobs between the two. It's an unfair situation as a prerequisite to many specialist registrar positions in dentistry is to have a broad base training in many areas.

A. Ahmad

Chester

\section{SHO pay scales}

Sir, I'm writing to say that SHO pay scales are a consistent problem in many health care trusts for dentists pursuing a hospital career.

A circular (gateway ref 2482) from the Department of Health by Jerry Read, states 'From January 1st 2004 dentists who have completed vocational training in the GDS and whom take up SHO posts should be placed on point 1 of the SHO pay scale and not 0'. So all new SHOs take note!

In my particular case I completed the following:

- Vocational training 12 months

- General professional training on an approved scheme

- Six months community and six months SHO restorative

- Community dental officer 11 months

- SHO oral and maxillofacial surgery 12 months - my current job.

Despite submitting all my experience my current health authority still placed me on SHO point ${ }^{1}$. Firstly I explained how vocational training counts towards point 0 , but I was surprised to be told if you have done VT prior to 1 January 2004 it may not.

Secondly, if VT counts as point 0 then surely GPT counts as point 1 regardless of whether you have done six months community and six months SHO or a full year as an SHO?

The third problem I faced was that if you do a community job you still seem to get nowhere on the SHO pay scale if you then decide to return to hospital.

I contacted the BDA who then kindly put me through to a regional BMA employment adviser. The adviser suggested I should be on POINT 3 of the pay scale and that all my past work which had been entirely in the community and hospital services is protected pay. This is
The BDJ Editor-in-Chief Stephen Hancocks responds: The BDA does not deal directly in cases involving starting pay for SHOs but has a contract with the BMA to take cases for BDA members working within the hospital service. Arrangements for starting pay at SHO are nevertheless not always straightforward, depending on previous experience in the NHS and where a member will have gained their experience or time in VT. Consequently, the BDA advise all members looking to take up SHO posts to contact the BMA for advice before taking up an appointment.

doi: $10.1038 /$ sj.bdj.4812857

\section{Patient individuality}

Sir, I read with interest the article by Irfan Ahmad on anterior dental aesthetics (BDJ 2005; 199: 135-141). In the article he associates gender with dental aesthetics. This perceived association between gender and tooth morphology/arrangement is commonly misunderstood. There does not appear to be any physical basis for this association. ${ }^{1}$ I feel this should be emphasised when suggesting general rules which may or may not apply to individuals. However, the author is right in suggesting that contemporary society deems some tooth arrangements 'masculine' and some tooth arrangements 'feminine. ${ }^{2}$ I am sure the author will agree that these general 'rules' (perhaps 'guidelines' would be a more appropriate term?) of morphopsychology should be abandoned rapidly in the face of patient individuality.

\section{T. P. Hyde}

Leeds

1. Hyde TP, McCord F, Macfarlane T, Smith J. Gender aesthetics in the natural dentition. Eur J Prosthodont Restor Dent 1999; 7: 27-30.

2. Hyde TP, Smith J. Gender, opinion and prejudice in aesthetic prosthodontics. Poster presented to BSSPD annual conference, 2001

doi: 10.1038/sj.bdj.4812858 


\section{Ozone revolution?} Or emperor's new clothes?

Sir, the concepts of minimally invasive dentistry and the concepts of remineralisation are well accepted. But I find it difficult to agree with the conclusions of the reviewer of Ozone: The revolution in dentistry $(B D J$ 2005; 199: 307) that it is a 'must have' text for twenty-first century dentists.

While ongoing studies may in the future show that this is an effective technique, the current state of the evidence is far from convincing. The book's foreword states:

'Recent technical advances have made it possible for ozone, a powerful disinfectant, to be applied to small areas of dental hard tissues while neighbouring tissues and the lungs are protected from this aggressive gas. Its effectiveness has been demonstrated in several well-planned clinical studies. For example, a recently published clinical trial showed the reversal of root caries using ozone in a double-blind, randomized, and controlled 18-month trial.' ${ }^{1}$

This contradicts both the recent Cochrane review on Ozone therapy for the treatment of dental caries ${ }^{2}$ which concludes that "there is no reliable evidence that application of ozone gas to the surface of decayed teeth stops or reverses the decay process' and the NICE technology appraisal ${ }^{3}$ which found "that there was insufficient evidence on the effectiveness of HealOzone treatment for this technology to be recommended, except as part of well-designed RCTs'. I for one would not wish to purchase an ozone machine for the treatment of caries based on the currently available evidence.

D.Richards

\section{Director, Centre for Evidence-based Dentistry}

1. Clinical reversal of root caries using ozone, doubleblind, randomised, controlled 18-month trial. Gerodontology 2003: 20: 106-114.

2. Rickard G D, Richardson R, Johnson T, McColl D, Hooper L. Ozone therapy for the treatment of dental caries (Cochrane Review). In the Cochrane Library. Chichester: John Wiley, 2004, Issue 3.

3. HealOzone for the treatment of tooth decay (occlusal pit and fissure caries and root caries) National Institute for Health and Clinical Excellence Technology Appraisal 92. July 2005. http://www.nice.org.uk/page.aspx?o=265570

doi: 10.1038/sj.bdj.4812890

\section{Sleepless in Surbiton}

Sir, the wee small hours are perfect for shaking the intellectual feathers from a problem. Tonight's teaser is a review of a book entitled: Ozone: The revolution in dentistry. ${ }^{1} \mathrm{I}$ am uneasy. The review is glowing, apparently, written by a born again ozone convert who feels the technique will permanently change the face of dentistry for the better. However, the reviewer seems uncritical of the evidence base and apparently unaware of both a Cochrane review ${ }^{2}$ and an appraisal by The National Institute for Clinical Excellence (NICE) ${ }^{3}$ which both concluded that evidence of efficacy is currently lacking. The Editor of the $B D J$ will be aware of the wider picture so should he have published this review? Perhaps not.

The review will certainly stimulate discussion and the Editor considers this is always good. However, I could go on a naked ramble in Surbiton High Street and stimulate discussion, but it would not be that good to make such an idiot of myself. The problem with the written word is that it is there for all to see, for ever. The Editor of the $B D J$ is steering the flagship of British dentistry and I am a little embarrassed that this has slipped through the editorial net to land on the page in perpetuity. This is not to say I am averse to controversy. The journal has often published peer reviewed research that flies in the face of mainstream opinion. The papers considering the restorative management of deciduous teeth are an excellent example of challenging work that demands attention. ${ }^{4-6}$ However, these papers are fully discussed in the light of research evidence and gaps in the knowledge base are probed and acknowledged. They are fascinating because they are written critically and they should stimulate further research.

So what should an Editor do when sent such a book to review? One approach would be to return it to the publishers but perhaps this is ducking responsibility. Another is to take the present course and publish what is sent without comment or criticism leaving it to the letters column to pick up the argument. Maybe a better approach would have been to have the book reviewed by someone whose job it is to be conversant with the evidence so that a more balanced review could be presented - and here the Editor must be careful to obtain balance not bias. It is getting early and I need some sleep - time to count sheep jumping over gates or maybe naked Editors over hot air would be more fun.

\section{E. Kidd}

\section{Surbiton}

1. Ozone: the revolution in dentistry. Book review. $\mathrm{Br}$ Dent J 2005; 199: 307

2. Rickard G D, Richardson R, Johnson T, McColl D, Hooper L. Ozone therapy for the treatment of dental caries (Cochrane review). Issue 3. In the Cochrane Library. Chichester: John Wiley, 2004.

3. Healozone for the treatment of tooth decay (occlusal pit and fissure caries and root caries). Technology Appraisal 92. National Institute for Health and Clinical Excellence. www.nice.org.uk/TA092.

4. Milsom K M, Tickle M, Blinkhorn A S. Dental pain and dental treatment of young children attending the general dental service. Br Dent J 2002; 192: 280-284.

5. Tickle M, Milsom K M, King D. Kearney-Mitchell P, Blinkhorn AS. The fate of carious primary teeth of children who regularly attend the general dental services. Br Dent J 2002; 192: 219-223.

6. Levine R S, Pitts N B, Nugent Z J. The fate of 1,587 unrestored carious deciduous teeth: a retrospective general practice based study from Northern England. Br Dent J 2002; 193: 99-103.

doi: $10.1038 /$ sj.bdj.4812890 